\title{
FORMULATION AND IN VIVO PHARMACOKINETIC STUDIES OF ILOPERIDONE DEPOT INJECTION
}

\author{
VINEET DUBEY and TULSI RAM SAINI*
}

Industrial Pharmacy Research Lab, Department of Pharmacy, Shri G. S. Institute of Technology and Science, Indore, India

\begin{abstract}
Iloperidone is a new antipsychotic agent having good tolerability and side-effects profile with respect to long term drug administration. Presently, it is only available as tablet dosage forms of 1-12 mg strengths for twice a day administration. This article reports the pharmacokinetic studies of a novel in situ depot injection formulation of iloperidone developed for once a month administration. The formulation is based on the use of sucrose acetate isobutyrate as a gelling agent for depot formation in situ. It is simple to prepare, possesses an acceptable syringeability and exhibits a controlled and consistent zero order drug release in vitro for one month. The in vivo pharmacokinetic studies performed in male albino Wistar rats for one month showed a mean peak plasma drug concentration of $871.8 \mathrm{ng} / \mathrm{mL}$ in 3 days, a mean residence time of 28.9 days, the terminal half-life of 24 days, and a terminal elimination rate-constant of $0.0289 /$ day. The plasma concentration profile of the developed formulation demonstrated a persistent plasma level of iloperidone for one month without any significant burst release and with a good in vitro - in vivo correlation.
\end{abstract}

Keywords: iloperidone, in vivo pharmacokinetic studies, in situ depot injection, sucrose acetate isobutyrate

Typical antipsychotic agents are known to produce severe extrapyramidal side effects and therefore are being gradually replaced by the safer atypical antipsychotic drug molecules. Presently, about fifteen atypical antipsychotic drugs such as olanzapine, risperidone, quetiapine, paliperidone, sertindole, and aripiprazole, etc. are in clinical use for the treatment of schizophrenia. Amongst these drugs, the long-acting depot formulations are commercially available for risperidone, paliperidone, olanzapine, and aripiprazole only (1). Iloperidone is a new atypical antipsychotic drug having better long term tolerability than other available atypical antipsychotic agents for the treatment of acute schizophrenia $(2,3)$. However, it is available only in conventional tablet form in 1-12 $\mathrm{mg}$ strengths for twice a day administration and its long-acting depot formulation is not available.

The clinical advantages of depot injection formulations in schizophrenia have been widely accepted due to their superiority over the conventional oral formulations. Non-adherence to dosage regimen of medication has been a major problem associated with psychotic patients (4). The depot injection formulations tremendously decrease the chances of discontinuation of treatment leading to optimal therapeutic management and substantial reduction in relapses of schizophrenia (5-7).

In situ depot injections basically being liquid compositions of a drug with a carrier and a solvent, offer many advantages over microspherical systems with respect to their ease of administration with minimal invasion, better tissue compatibility, and simplicity of preparation (8). The sucrose acetate isobutyrate is nowadays gaining wide popularity as release retarding carrier in the development of in situ depot injections as compared to expensive polylactic acid, polyglycolic acid polymers, and their derivatives $(9,10)$. This is due to its low cost, biodegradability, biocompatibility, and simple and scalable formulation technique as compared to microspheres and liposomal drug delivery systems $(11,12)$. It is a hydrophobic and viscous fluid and when dissolved in some organic solvent, transforms into a low viscosity syringeable injectable liquid preparation which when comes in the contact with aqueous environment in vitro or in vivo, regenerates into a viscous drug-containing matrix which would

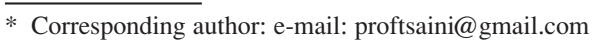


act as depot reservoir and yield a sustained drug release for a long duration $(13,14)$.

In the present study, an in situ depot injection formulation of iloperidone was developed using sucrose acetate isobutyrate as release retarding carrier and dimethyl sulphoxide, which belongs to the safer class 3 solvent category (15) and also listed in Inactive Ingredients Guide of United States Food and Drug Administration (USFDA) for intravenous infusion and subcutaneous implants (16), as solvent. After in vitro release testing the developed product was subjected to one month pharmacokinetic study in male albino Wistar rats after subcutaneous administration. The correlation between in vitro and in vivo drug release performance of the developed formulation was established by fractional AUC (area under the curve) method (17). The preparation and administration of the developed depot injection formulation are represented in Figure 1.

\section{EXPERIMENTAL}

\section{Materials}

Iloperidone was supplied by M/S Sun Pharmaceutical Industries Ltd., Mumbai, India, and sucrose acetate isobutyrate by $\mathrm{M} / \mathrm{S}$ Eastman Chemical Company, Kingsport, USA, as gift samples. Dimethyl sulphoxide was purchased from Qualigens Fine Chemicals, Mumbai. All other chemicals and solvents used were of analytical grade and procured from the market.
Particle size and polydispersity index of the drug

The mean particle size and polydispersity index of the iloperidone drug was determined using laser diffraction-based particle size analyzer (Malvern Mastersizer 2000, UK).

\section{Preparation of in situ depot injection formulation}

Sucrose acetate isobutyrate $(81.72 \% \mathrm{v} / \mathrm{v})$ was dissolved in dimethyl sulphoxide $(18.28 \% \mathrm{v} / \mathrm{v})$. Iloperidone drug powder was added $(6 \% \mathrm{w} / \mathrm{v})$ to the above solution and dispersed on a vortex mixer (CM101 Plus, Remi Lab World, India) to get a uniform suspension. The formulation was subjected to the following in vitro tests and in vivo pharmacokinetic studies.

\section{Visual appearance}

The formulated depot injection was visually inspected for color, consistency, homogeneity, and clarity.

\section{Density}

One $\mathrm{mL}$ of the formulated depot injection was accurately pipetted into a pre-weighed micropipette tip fitted in a $1 \mathrm{~mL}$ micropipette (Eppendorf) and weighed on an analytical balance (Shimadzu). The difference of the weights of the filled and empty micropipette tip was taken as the density of the formulation $(n=3)$.

\section{Effect on the pH of surrounding fluid}

The effect of formulated depot injection on the $\mathrm{pH}$ of the surrounding environmental fluid after its injec-

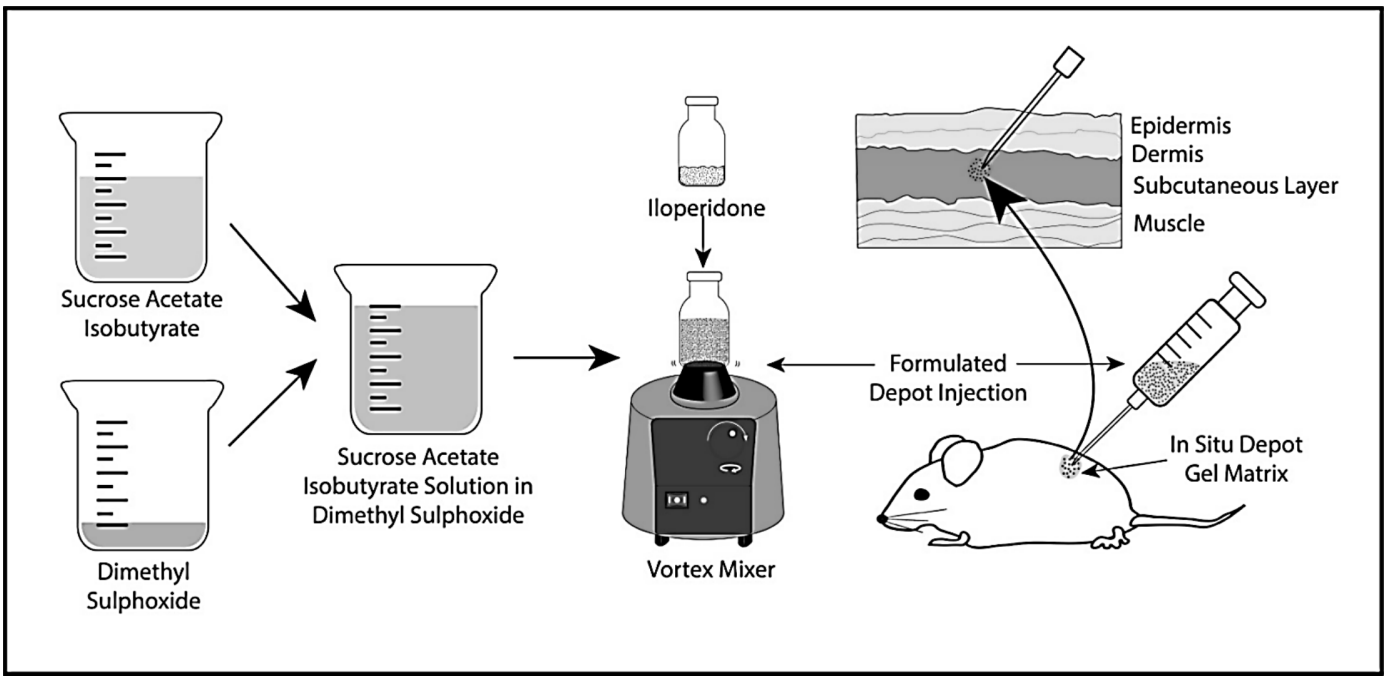

Figure 1. Preparation of in situ gel forming depot injection and its administration 


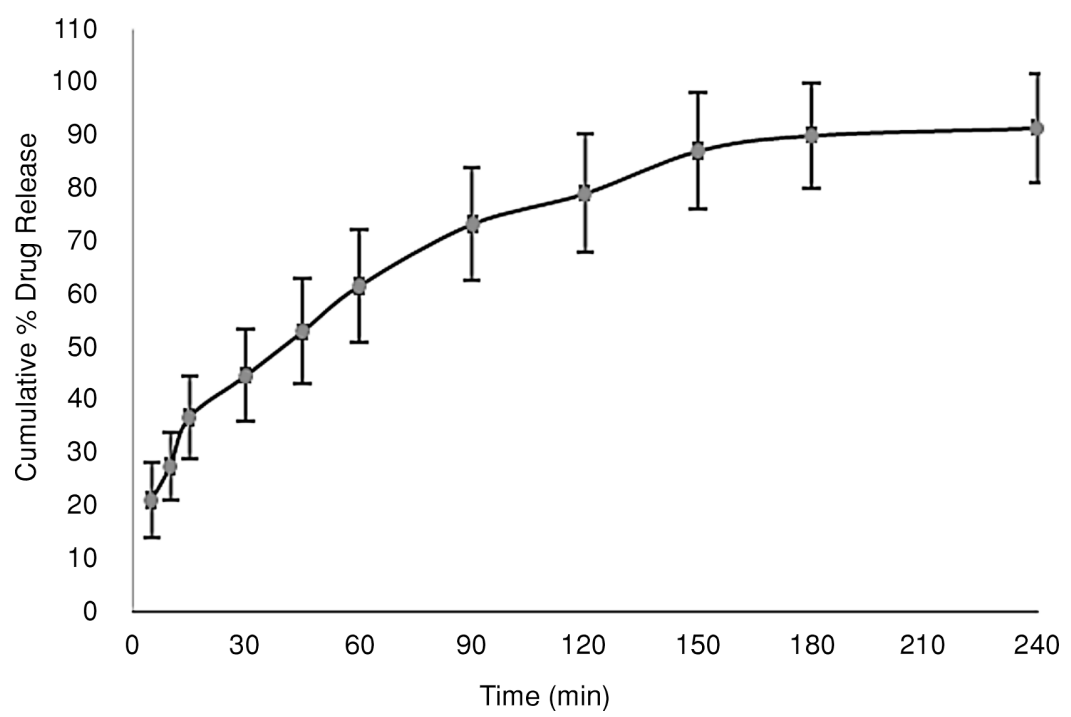

Figure 2. In vitro dissolution profile of marketed iloperidone tablets

tion was studied by injecting $1 \mathrm{~mL}$ product in $10 \mathrm{~mL}$ distilled water and then monitoring $\mathrm{pH}$ of the resulting aqueous fluid for one hour by a calibrated $\mathrm{pH}$ meter (Cyberscan pH 510, Thermo Fisher Scientific, USA).

\section{Viscosity}

The viscosity of the formulated depot injection was determined $(n=3)$ by Brookfield Rheometer (R/S-CPS Plus ${ }^{\mathrm{TM}}$, Brookfield Engineering, USA). The product sample was placed in the rheometer operated at $300 \mathrm{rpm}$ at room temperature and the viscosity was noted.

\section{Syringeability}

Syringeability measures the force required to inject a formulation through a needle of a particular gauge at a definite rate of injection. The syringeability of the formulated depot injection was determined by Texture Analyzer (TA.XT.Plus, Stable Micro Systems, UK). One $\mathrm{mL}$ product was taken in a $2 \mathrm{~mL}$ capacity plastic syringe fitted with 18,20 , and $21 \mathrm{G}$ needle respectively and the test was conducted with an injection speed of $1 \mathrm{~mm} / \mathrm{s}$ and injection distance of $5 \mathrm{~mm}$ at room temperature. The force required for displacing the plunger of the syringe was recorded by the software (Texture Exponent Lite) as syringeability of the developed formulation.

\section{In vitro drug release of marketed iloperidone tablet}

In order to assess drug release of marketed product the in vitro drug release study of marketed iloperidone tablets (Brand- Ilosure 4; B.No.: 8590780; Sun Pharma Laboratories Ltd., India) was conducted as per the method recommended for iloperidone tablets in USFDA Dissolution Method Database (18). The test was performed in USP dissolution test apparatus II (paddle) [EDT-08Lx, Electrolab, India] at $50 \mathrm{rpm}$ using $500 \mathrm{~mL}$ of $0.1 \mathrm{~N}$ $\mathrm{HCl}$ as dissolution medium. Samples of dissolution fluid were collected at different time points and replenished with an equal volume of fresh dissolution medium after each withdrawal. The samples were analyzed on a double beam UV-visible spectrophotometer (UV-1700, Shimadzu Corporation, Japan) at $276 \mathrm{~nm}$ and the cumulative percent drug dissolved at different time points was calculated.

\section{In vitro drug release of formulated depot injection}

The accurately weighed quantity of developed injection formulation was transferred into a $15 \mathrm{~mL}$ screw-capped plastic tube containing $10 \mathrm{~mL}$ dissolution medium and placed in an incubator shaker bath (SM Scientific Instruments, India) maintained at $37 \pm 1^{\circ} \mathrm{C}$ and $60 \pm 5 \mathrm{rpm}$ stirring speed (19). The phosphate buffered saline ( $\mathrm{pH} 7.4$ ) with $0.5 \%$ sodium lauryl sulfate as a surfactant and $0.05 \%$ sodium azide as a preservative was used as the dissolution medium to provide sink condition for the drug release. The iloperidone was found to be stable in this medium for one month period of study. At different time intervals, entire volume of dissolution fluid from each tube was withdrawn and replaced with an equal volume of fresh dissolution medium. 
The collected samples were analyzed for drug content on a double beam UV-visible spectrophotometer (UV-1700, Shimadzu Corporation, Japan) at 276 $\mathrm{nm}$ and the cumulative percent drug release at different time points was calculated.

\section{In vivo pharmacokinetic study}

The in vivo pharmacokinetic study was conducted on six healthy male albino Wistar rats of 160-200 g body weight with due approval of the Committee for the Purpose of Control and Supervision of Experiments on Animals (CPCSEA) (Approval number: CPCSEA/IAHVB/2017/01/02). The animals were housed in spacious cages for easy movement and given free access to food and water during the entire period of study. The developed depot injection formulation was subcutaneously injected (20) to each rat using a $20 \mathrm{G}$ needle at a dose of $50 \mathrm{mg} / \mathrm{kg}$ body weight. The blood samples $(0.3$ $\mathrm{mL}$ ) were collected at predefined time intervals from lateral tail vein (21) and transferred into centrifuge tubes containing a solution of disodium edetate as a anticoagulant and centrifuged at $5000 \mathrm{rpm}$ for $10 \mathrm{~min}$ at $4^{\circ} \mathrm{C}$ (Eppendorf 5415R Centrifuge, Eppendorf, Germany) to separate the plasma. The plasma samples were collected into fresh centrifuge tubes and stored at $-20^{\circ} \mathrm{C}$ until analyzed.

\section{Sample preparation}

Each plasma sample stored at $-20^{\circ} \mathrm{C}$ was first thawed at room temperature and mixed well with three times its volume of acetonitrile on a vortex mixer (CM-101 Plus, Remi Lab World, India) for 5 min to precipitate plasma proteins and then centrifuged at $5000 \mathrm{rpm}$ for $10 \mathrm{~min}$ at $4^{\circ} \mathrm{C}$ (Eppendorf 5415R Centrifuge, Eppendorf, Germany). The separated supernatant was collected in another tube and then subjected to high-performance liquid chromatography (HPLC) analysis.

\section{HPLC analysis:}

The prepared plasma samples were analyzed for drug content on a reverse phase HPLC system (Waters Corporation, USA) using Waters 2996 photodiode array detector, Empower software, and a $4.6 \times 250 \mathrm{~mm}$; particle size $5 \mu \mathrm{m} \mathrm{C}_{18}$ BDS Hypersil Phenyl column (Thermo Fisher Scientific Inc., USA). The mobile phase consisted of acetonitrile and phosphate buffer $\mathrm{pH} 6.0(40: 60 \mathrm{v} / \mathrm{v})$ with a flow rate of $1.5 \mathrm{~mL} / \mathrm{min}$. The injection volume was $20 \mu \mathrm{L}$ and the detection wavelength of $276 \mathrm{~nm}$. This method of analysis has had the lower limit of quantification (LLOQ) of $50 \mathrm{ng} / \mathrm{mL}$ and demonstrated linearity over the concentration range of 50-1000 $\mathrm{ng} / \mathrm{mL}$ (22).

\section{Statistical data analysis:}

A plasma drug concentration-time curve was constructed by plotting the plasma drug concentration against time. The peak plasma drug concentration $\left(\mathrm{C}_{\max }\right)$ and time to achieve peak plasma drug concentration $\left(\mathrm{T}_{\max }\right)$ were directly obtained from the

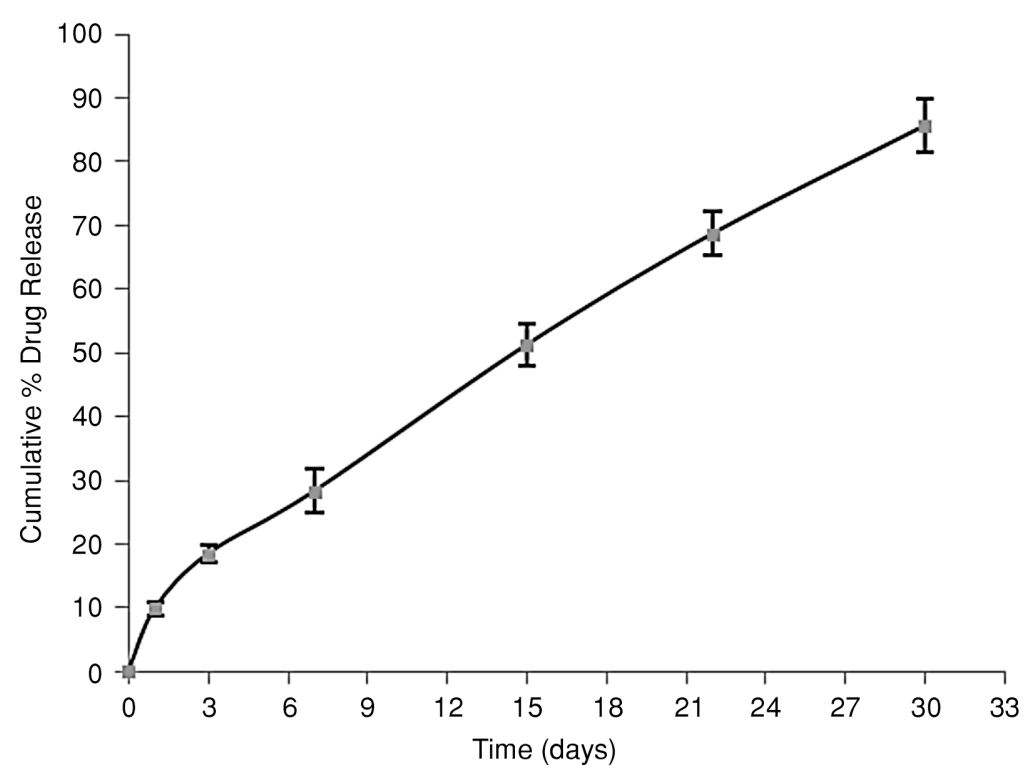

Figure 3. In vitro drug release of developed depot injection of iloperidone 


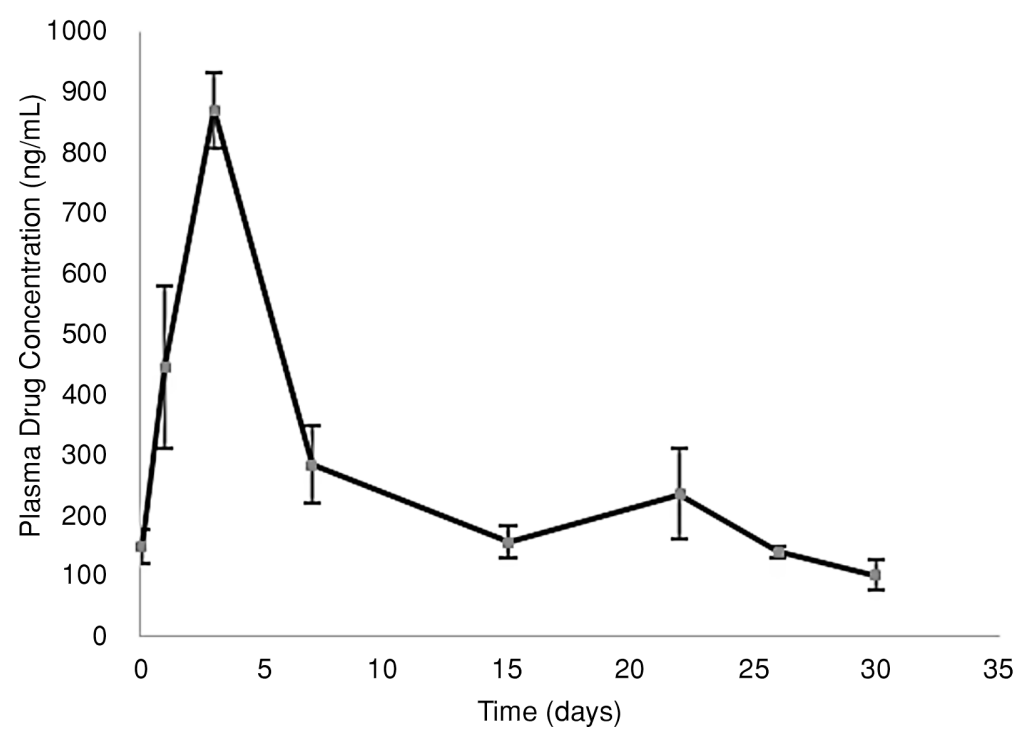

Figure 4. In vivo pharmacokinetic profile of iloperidone after subcutaneous administration of developed in situ depot injection to rats $(\mathrm{n}=6)$

graph and the area under the plasma drug concentration-time curve $\left(\mathrm{AUC}_{0-30 \mathrm{~d}}\right)$ was calculated by trapezoidal method (23). The plasma drug concentration-time data were represented by non-compartmental pharmacokinetic model for extravascular administration (24-26) and the terminal elimination rate constant $\left(\lambda_{z}\right)$, terminal elimination half-life $\left(t_{1 / 2}\right)$, mean residence time (MRT), apparent volume of distribution after extravascular administration $\left(\mathrm{V}_{\mathrm{z}} / \mathrm{F}\right)$, and total apparent clearance of the drug from plasma after extravascular administration $(\mathrm{Cl} / \mathrm{F})$ were calculated using Kinetica software (Version 5.0, Adept Scientific, UK).

\section{In vitro - in vivo correlation}

The in vitro- in vivo correlation (IVIVC) provides in vivo relevance to the in vitro drug release data, reduces the period of drug development, helps in quality control for scale-up and post-approval changes, and supports in the grant of biowaiver in new product development (27).

In the present study, the IVIVC between in vitro drug release and the plasma concentration data was established by fractional AUC method (17). The fractional AUC was calculated by dividing AUCs at different time intervals with cumulative AUC till last time point and the percent fractional AUC was plotted against the in vitro cumulative percent drug release and the correlation coefficient was calculated to assess the extent of IVIVC $(23,28)$.

\section{RESULTS}

Particle size and poly-dispersity index of the drug The mean particle-size of iloperidone drug present in the depot formulation was found to be $7.734 \mu \mathrm{m}$ with a polydispersity index of 2.323 .

\section{Visual appearance}

The formulated depot injection was a slightly off white colored viscous liquid dispersion.

\section{Density}

The density of the formulated depot injection was found to be $1.135 \pm 0.013 \mathrm{~g} / \mathrm{mL}(\mathrm{n}=3)$.

\section{Effect on the $\mathbf{p H}$ of surrounding fluid}

When the formulated depot injection was injected into $10 \mathrm{~mL}$ of distilled water to form an in situ gel depot, the $\mathrm{pH}$ of the distilled water remained unchanged at $7.0 \pm 0.5$ during $1 \mathrm{~h}$ of study. This implies that the presence of the formulated depot injection at the site of injection would not alter the $\mathrm{pH}$ of the surrounding fluid.

\section{Viscosity}

The viscosity of depot injections plays an important role in controlling the burst release but at the same time, it adversely affects the syringeability of the formulation (29). The viscosity of sucrose acetate isobutyrate is $\sim 100,000 \mathrm{mPas}$ but after dilution with $15-35 \%$ of organic solvents, it gets low- 
ered to 50-200 mPas (12). In the present study, the viscosity of the formulated depot injection was found to be $151.37 \pm 21.99 \mathrm{mPas}(\mathrm{n}=3)$ at room temperature.

\section{Syringeability}

The injection force required to expel the formulated depot injection from the syringe was found to increase with an increase in the needle gauze size and was in order of $21 \mathrm{G}>20 \mathrm{G}>18 \mathrm{G}>16 \mathrm{G}$ and was measured as $135 \mathrm{~N}, 75 \mathrm{~N}, 25 \mathrm{~N}$, and $10 \mathrm{~N}$ respectively for $21 \mathrm{G}, 20 \mathrm{G}, 18 \mathrm{G}$, and $16 \mathrm{G}$ needles. The needle gauge size recommended for intramuscular administration is $20-23 \mathrm{G}$ (30) and the formulated depot injection was readily syringeable through a $20 \mathrm{G}$ needle.

\section{In vitro dissolution study of marketed iloperidone tablet}

The dissolution profile of the marketed tablets of iloperidone (4 mg strength) depicted in Figure 2 shows that $90 \%$ drug release took place within four hours. Although the half-life of iloperidone is $18-33 \mathrm{~h}$ (31) which indicates that its once a day dosage regimen is possible, but in order to minimize the orthostatic hypotension in the uptitration phase the iloperidone tablets are administered twice a day (3). This outweighs the advantage of its longer half-life and the need for a long-acting formulation becomes even more apparent.

\section{In vitro drug release of developed in situ depot injection}

Figure 3 shows one month in vitro drug release profile of the formulated depot injection. First day approximately $10 \%$ drug was released and after 30 days the cumulative drug release was around $86 \%$. The graph was linear $\left(\mathrm{R}^{2}=0.985\right)$ with the values of intercept and slope equal to 6.889 and 2.745 respectively.

\section{In vivo pharmacokinetic study:}

The plasma levels attained by the developed depot injection with respect to time are shown in Figure 4. The mean peak plasma drug concentration of $871.8 \mathrm{ng} / \mathrm{mL}$ was attained after 3 days of drug administration which subsequently declined to 284 $\mathrm{ng} / \mathrm{mL}$ on the $7^{\text {th }}$ day. The plasma drug concentration was maintained between $139 \mathrm{ng} / \mathrm{mL}$ and $235 \mathrm{ng} / \mathrm{mL}$ concentration range during 15 to 26 days of administration and afterward decreased to $101 \mathrm{ng} / \mathrm{mL}$ on the $30^{\text {th }}$ day. This shows that the developed depot injection could sustain the drug release for a duration of one month.

The pharmacokinetic parameters obtained from plasma drug concentration data are enlisted in

Table 1. Pharmacokinetic parameters of the developed depot injection of iloperidone.

\begin{tabular}{|c|c|c|c|c|c|c|c|c|}
\hline $\begin{array}{c}\text { Pharmacokinetic } \\
\text { Parameter }\end{array}$ & $\begin{array}{c}\mathrm{C}_{\max } \\
(\mathrm{ng} / \mathrm{mL})\end{array}$ & $\begin{array}{c}\mathrm{T}_{\max } \\
(\mathrm{d})\end{array}$ & $\begin{array}{c}\mathrm{AUC}_{0-30 \mathrm{~d}} \\
(\mathrm{ng} . \mathrm{d} / \mathrm{mL})\end{array}$ & $\begin{array}{c}\lambda_{\mathrm{z}} \\
(1 / \mathrm{d})\end{array}$ & $\begin{array}{c}\mathrm{t}_{1 / 2} \\
(\mathrm{~d})\end{array}$ & $\begin{array}{c}\mathrm{MRT} \\
(\mathrm{d})\end{array}$ & $\begin{array}{c}\mathrm{V}_{\mathrm{z}} / \mathrm{F} \\
(\mathrm{L} / \mathrm{Kg})\end{array}$ & $\begin{array}{c}\mathrm{Cl} / \mathrm{F} \\
(\mathrm{L} / \mathrm{d} . \mathrm{Kg})\end{array}$ \\
\hline Value & $871.8 \pm 64$ & 3 & $8276 \pm 1483$ & 0.0289 & 24 & 28.9 & 145.3 & 4.2 \\
\hline
\end{tabular}

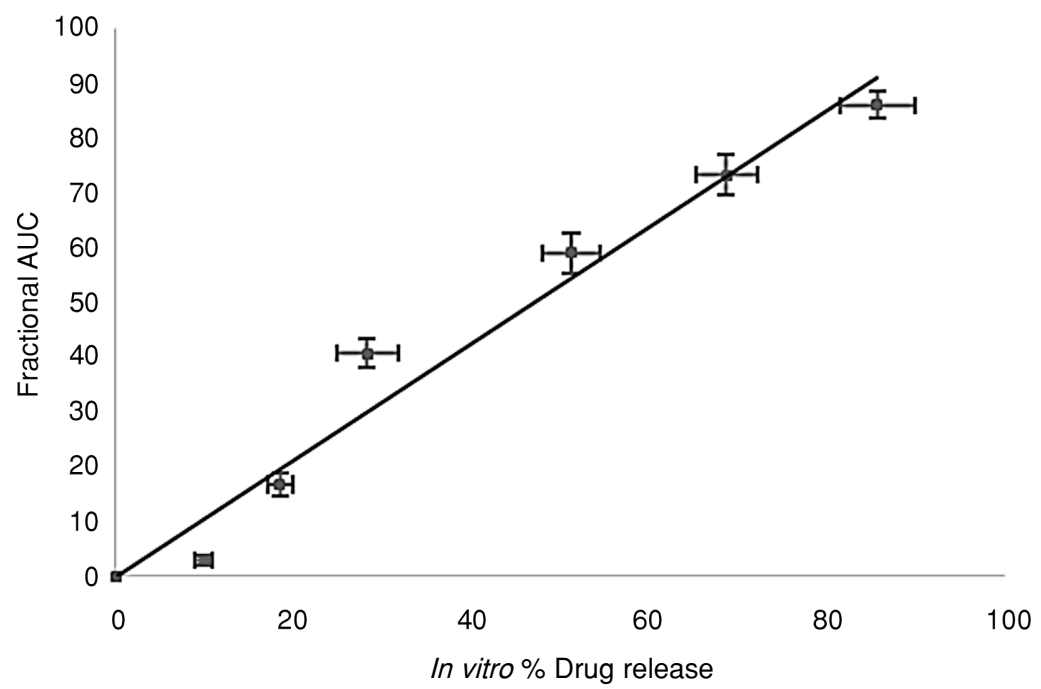

Figure 5. In vitro - in vivo correlation of the developed depot injection of iloperidone 
Table 1. The $\mathrm{C}_{\max }$ and $\mathrm{AUC}_{0-30 \mathrm{~d}}$ are reported as mean \pm standard deviation while the other pharmacokinetic parameters are as obtained from Kinetica software using mean values.

\section{DISCUSSION AND CONCLUSION}

The in vitro cumulative drug release profile of the developed depot injection followed a predominantly zero order drug release kinetics with a correlation coefficient of 0.985 . The intercept of the graph signifies the initial burst release of $6.89 \%$ which is equivalent to $2.07 \mathrm{mg}$ drug release on the first day and the drug release flux obtained from the slope of the graph was $2.74 \% / \mathrm{d}$ which is equivalent to $0.82 \mathrm{mg} / \mathrm{d}$.

The in vivo pharmacokinetic profile exhibited a sustained drug release from the developed depot injection over a period of one month as evident from the mean residence time of 28.9 days, without any prominent burst release. The developed depot formulation was basically a suspension of iloperidone in sucrose acetate isobutyrate-dimethyl sulphoxide solution. Therefore, the sustained drug release observed from the formulation can be mainly attributed to the release retarding barrier properties of the in situ gel depot matrix formed by sucrose acetate isobutyrate. The drug particles suspended in the matrix acted as reservoirs and continuously dissolved in order to maintain a constant drug release flux from the matrix to the surrounding fluid to restore the diffused amount (32-34). The suspensions are known to cause slower absorption than solutions and result in a zero order drug absorption profile (35). In addition, as the time elapsed, the biodegradation of sucrose acetate isobutyrate must also have begun and after four days of administration would slowly have started contributing to the enhancement in drug release from gel depot matrix (36).

The observed nominal initial burst release could be mainly due to the presence of small amount of drug in the dissolved form in dimethyl sulphoxide present in the formulation which would have got released in the surrounding fluid in vivo soon after the injection and also partly due to little time lag manifested in the depot formation.

\section{In vitro- in vivo correlation:}

The graph between fractional AUC of plasma concentration profile and in vitro cumulative percent drug release of the formulated depot injection at different time points as shown in Figure 5 is almost linear over 0-30 days with a correlation coefficient of
0.968 indicating a good correlation between the in vitro and in vivo drug release profiles (37). The IVIVC is, however, more pronounced during 7-30 days with $\mathrm{R}^{2}=0.999$.

In conclusion, the in vivo pharmacokinetic studies of the developed in situ gel forming depot injection of iloperidone revealed a long-term sustained drug release potential of the formulation with a mean residence time of 28.9 days and halflife of 24 days. It showed a $\mathrm{C}_{\max }$ of $871.8 \mathrm{ng} / \mathrm{mL}$ and $\mathrm{T}_{\max }$ of 3 days with a nominal burst release. The developed formulation is a simple to prepare in situ gel forming depot injection of iloperidone based on a low-cost biodegradable release retarding excipient sucrose acetate isobutyrate and class 3 solvent dimethyl sulphoxide. All relevant pharmaceutical properties of the formulation including syringeability and viscosity were in the acceptable limits and a close to zero order in vitro drug release along with a good in vitro- in vivo correlation was demonstrated.

\section{Acknowledgment}

Authors thankfully acknowledge Director, Institute of Animal Health \& Veterinary Biologicals, Mhow, District Indore, India for granting the permission to conduct in vivo pharmacokinetic studies on rats, M/S Sun Pharmaceutical Industries Ltd., Mumbai, India for the gift sample of iloperidone, and M/S Eastman Chemical Company, Kingsport, USA for the gift sample of sucrose acetate isobutyrate.

\section{Conflict of interest}

The authors declare that they have no conflict of interest.

\section{REFERENCES}

1. Sacchetti E., Grunez H., Leucht S., Vita A.: Evidence-Based Psychiatric Care 1, 27 (2015).

2. Cutler A.J., Kalali A.H., Weiden P.J., Hamilton J., Wolfgang C.D.: J. Clin. Psychopharmacol. 28, S20 (2008).

3. Weiden P.J.: Clin. Schizophr. Relat. Psychoses. 6, 34 (2012).

4. Kane J.M., Kishimoto T., Correll C.U.: World Psychiatry 12, 216 (2013).

5. Devito R.A., Brink L., Sloan C., Jolliff F.: J. Clin. Psychiatry. 39, 26 (1978).

6. Offord S., Wong B., Mirski D., Baker R.A., Lin J.: J. Med. Econ. 16, 231 (2013). 
7. Biagi E., Capuzzi E., Colmegna F., Mascarini A., Brambilla G. et al.: Adv. Ther. 34, 1036 (2017).

8. Agarwal P., Rupenthal I.D.: Drug. Discov. Today. 18, 337 (2013).

9. Hatefi A., Amsden B.: J. Control. Release 80, 9 (2002).

10. Okumu F.W., Dao le N., Fielder P.J., Dybdal N., Brooks D. et al.: Biomaterials. 23, 4353 (2002).

11. Packhaeuser C.B., Schnieders J., Oster C.G., Kissel T.: Eur. J. Pharm. Biopharm. 58, 445 (2004).

12. Kempe S., Mader K.: J. Control. Release 161, 668 (2012).

13. Strickley R.G.: Pharm. Res. 21, 201 (2004).

14. Arthur J.T.: Sucrose Acetate Isobutyrate (SAIB) for Parenteral Delivery, in ModifiedRelease Drug Delivery Technology. Rathbone M.J., Hadgraft J., Roberts M.S. Eds., pp. 679687, Marcel Dekker Inc., New York 2002.

15. https://www.fda.gov/downloads/drugs/guidances/ucm073395.pdf (accessed on 03. 07. 2017)

16. https://www.accessdata.fda.gov/scripts/cder/iig (accessed on 06. 03. 2017).

17. Shen J., Burgess D.J.: J. Control. Release 219, 644 (2015).

18. https://www.accessdata.fda.gov/scripts/cder/ dissolution/index.cfm (accessed on 08. 06. 2017).

19. Conti B., Genta I., Giunchedi P., Modena T.: Drug. Develop. Ind. Pharm. 21, 1223 (1995).

20. Turner P.V., Brabb T., Pekow C., Vasbinder M.A.: J. Am. Assoc. Lab. Anim. Sci. 50, 600 (2011).
21. Diehl K.H., Hull R., Morton D., Pfister R., Rabemampianina Y. et al.: J. Appl. Toxicol. 21, 15 (2001).

22. Dubey V., Saini T.R.: Int. J.Pharm. Sci. Res.9, 790 (2018).

23. D’Souza S., Faraj J.A., Giovagnoli S., DeLuca P.P.: Int. J. Biomater. 2014, 1 (2014).

24. Lu Y., Tang X., Cui Y., Zhang Y., Qin F., Lu X.: Eur. J. Pharm. Biopharm. 68, 422 (2008).

25. Nahata T., Saini T.R.: PDA J. Pharm. Sci. Technol. 63, 113 (2009).

26. Shi X., Lin X., Yao C., Shen L., Feng Y.: Int. J. Biol. Macromol. 72, 553 (2015).

27. Emami J.: J. Pharm. Pharm. Sci. 9, 169 (2006).

28. Chu D.F., Fu X.Q., Liu W.H., Liu K., Li Y.X.: Int. J. Pharm. 325, 116 (2006).

29. Guo J., Wang J., Cai C., Xu J., Yu H. et al.: AAPS PharmSciTech. 16, 973 (2015).

30. Heller M., Veach L.M.: Administration of Parenteral Medications, in Clinical Medical Assisting: A Professional, Field Smart Approach to the Workplace. pp. 851-852, Cengage Learning, Boston 2008.

31. Citrome L.: Expert Opin. Drug Metab. Toxicol. 6, 1551 (2010).

32. Higuchi T.: J. Pharm. Sci. 50, 874 (1961).

33. Lu Y., Yu Y., Tang X.: J. Pharm. Sci. 96, 3252 (2007).

34. Wang L., Wang A., Zhao X., Liu X., Wang D. et al.: Int. J. Pharm. 427, 284 (2012).

35. Chien Y.W.: Parenteral Controlled-Release Drug Administration, in Novel Drug Delivery Systems. Chien Y.W. Ed., pp. 219-310, Marcel Dekker Inc., New York 1982.

36. Lin X., Xu Y., Tang X., Zhang Y., Chen J. et al.: Pharm. Res. 32, 3708 (2015).

37. Mukaka M.M.: Malawi Med. J. 24, 69 (2012).

Received: 15.03. 2018 